\title{
2005 Sōmiya Award Honors Terence G. Langdon and Zenji Horita
}

The International Union of Materials Research Societies (IUMRS) has presented the 2005 Sōmiya Award to Terence G. Langdon of the University of Southern California, Los Angeles, and to Zenji Horita of Kyushu University, Fukuoka, Japan, for their collaboration on severe plastic deformation as a means of processing materials. Horita accepted the award on July 5 in Singapore during the 3rd International Conference on Materials for Advanced Technologies (ICMAT 2005) \& 9th International Conference on Advanced Materials (IUMRS-ICAM 2005), hosted by the Materials Research Society of Singapore. Langdon was unable to attend the ceremonies.

Severe plastic deformation (SPD) is a processing approach that refines grains and other structural features through plastically deforming materials to a very large strain. Horita and Langdon, through their collaborative research effort, have established equal-channel angular pressing (ECAP) as a major method for the production of nanocrystalline materials, developing it as a standardized research tool and using it to probe the properties of these materials in exquisite detail. The awards committee recognized the development of ECAP as the research team's major achievement.

The collaboration has lasted a decade and a half, and continues unabated. Among its many spin-offs are the nanoSPD Web-based networking project (www.nanospd.org) tying together the many workers around the world who focus on severe plastic deformation. According to the awards committee, almost everyone worldwide who works on this topic has, at one time or another, had some kind of a collaboration with Horita and Langdon, who form the core team for this research topic.

The Sōmiya Award recognizes the achievement of a team of researchers that has collaborated across two or more continents during the past decade whose work is not only of the highest quality and well recognized by the international materials community, but has also had a demonstrated major impact on technology or society. Over the past 15 years, Langdon and Horita have jointly authored more than 200 papers, some of which have been highly cited by other authors. In the most

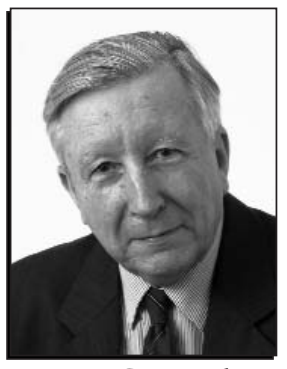

Terence G. Langdon

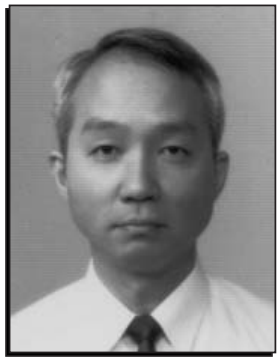

Zenji Horita

recently published announcement by the Institute for Scientific Information (ISI) of the most-cited researchers in materials science for publications over the past 10 years, Langdon and Horita are ranked at the \#2 and \#6 positions, respectively.

Langdon is the William E. Leonhard Professor of Engineering and a professor of aerospace and mechanical engineering, materials science, and earth sciences at the University of Southern California. He was appointed as an associate professor in 1971 and promoted to full professor in 1976. Langdon has served in professorial appointments at many institutions internationally, including the University of Melbourne, the Universidad Nacional Autónoma de Mexico, the University of New South Wales, and the Danish Technical University. He has been a visiting scientist at the Risø National Laboratory in Denmark, Kyushu University in Japan, and the University of Southampton in the United Kingdom, and he has been a visiting senior fellow at the International Center for Advanced Studies in Nizhny Novgorod, Russia.

Among Langdon's awards and honors are a DSc degree in physics from the University of Bristol and election to fellow in the American Ceramic Society; ASM International; the Institute of Materials, Minerals, and Mining; the Institute of Physics; the Minerals, Metals \& Materials Society (TMS), and election as honorary member of the Japan Institute of Metals. In 1994, he was only the fourth foreigner to be appointed as an honorary academician of the Academy of Sciences of the Bashkortostan Republic (Russia). More recently, he was awarded the Henry Marion Howe Medal by ASM International and the Structural Materials Division Distinguished Scientist/Engineer
Award by TMS, elected a fellow of the Royal Academy of Engineering in the United Kingdom., and awarded the degree of doctor honoris causa by the Russian Academy of Sciences in 2003.

Langdon serves on the editorial advisory board of Materials Science and Engineering A, Journal of Materials Science, and Scientia Iranica, and on the editorial board of Materials Science Forum and the Journal of High-Temperature Materials and Processes. He obtained his $\mathrm{PhD}$ degree in physical metallurgy from Imperial College, University of London, in 1965.

Horita is a professor in the Department of Materials Science and Engineering at Kyushu University, where he began his tenure in 1990 as associate professor, and before that as a research associate (19841990). Horita obtained his BS and MS degrees from Kyushu, and his $\mathrm{PhD}$ degree from the University of Southern California in 1983 . He continued at USC as a postdoctoral research associate from 1983 to 1984 before returning to Japan. Horita held concurrent appointments as a visiting scientist at USC (1987), a visiting professor at the Center for Solid-State Science at Arizona State University (1991-1992), and in the Department of Mechanics at the University of Ancona, Italy (2003). He is currently a program officer in Japan's Ministry of Science and Education.

Among Horita's most recent honors are the Koseki Award from the Japan Institute of Metals, the Seto Award from the Japanese Society of Electron Microscopy, and the Metals and Materials Science Award from the Metals Research Foundation.

Horita served as executive editor of the Journal of Electron Microscopy (1998-2000) and currently serves as editor of the Journal of Japan Institute of Metals and the Journal of Japan Institute of Light Metals.

The Sōmiya Award is named in honor of Shigeyuki Sōmiya, professor emeritus of the Tokyo Institute of Technology and former dean at Teikyo University of Science and Engineering, who pursued joint research work with colleagues in Europe and the United States and brought many international materials gatherings to Japan.

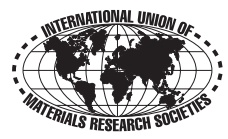




\section{E-MRS Announces Call for Symposium Topics for 2006 Fall Meeting}

The European Materials Research Society (E-MRS) is seeking proposals for symposium topics for the 2006 E-MRS Fall Meeting to be held September 4-8 in Warsaw, Poland. Submitted proposals (1-2 pages) should include the motivation and scope of the proposal with the name of the proposed symposium chairperson and 2-5 organizers from different countries.
At least nine symposium topics are expected; five have already been selected: - wide bandgap II-VI semiconductors: growth, characterization, and applications; - complex oxide materials for new technologies;

- nanostructured composite films: synthesis, characterization, properties, and applications;
- multiscale kinetic modeling of materials; and

- polymeric materials modified by nanoparticles.

Proposals should be sent by e-mail to Warsaw.fall@e-mrs.org.

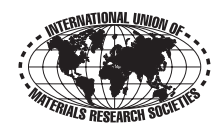

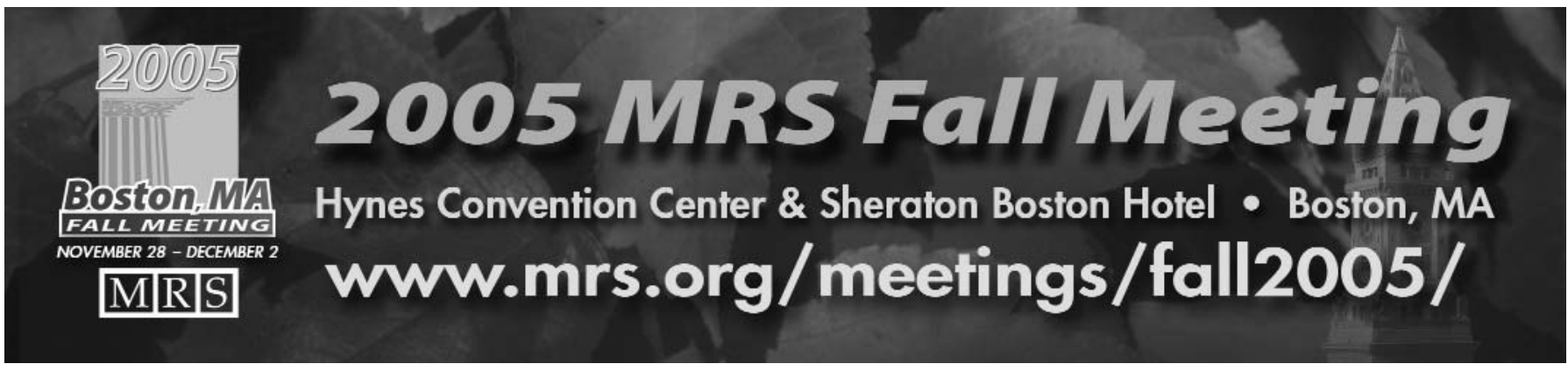

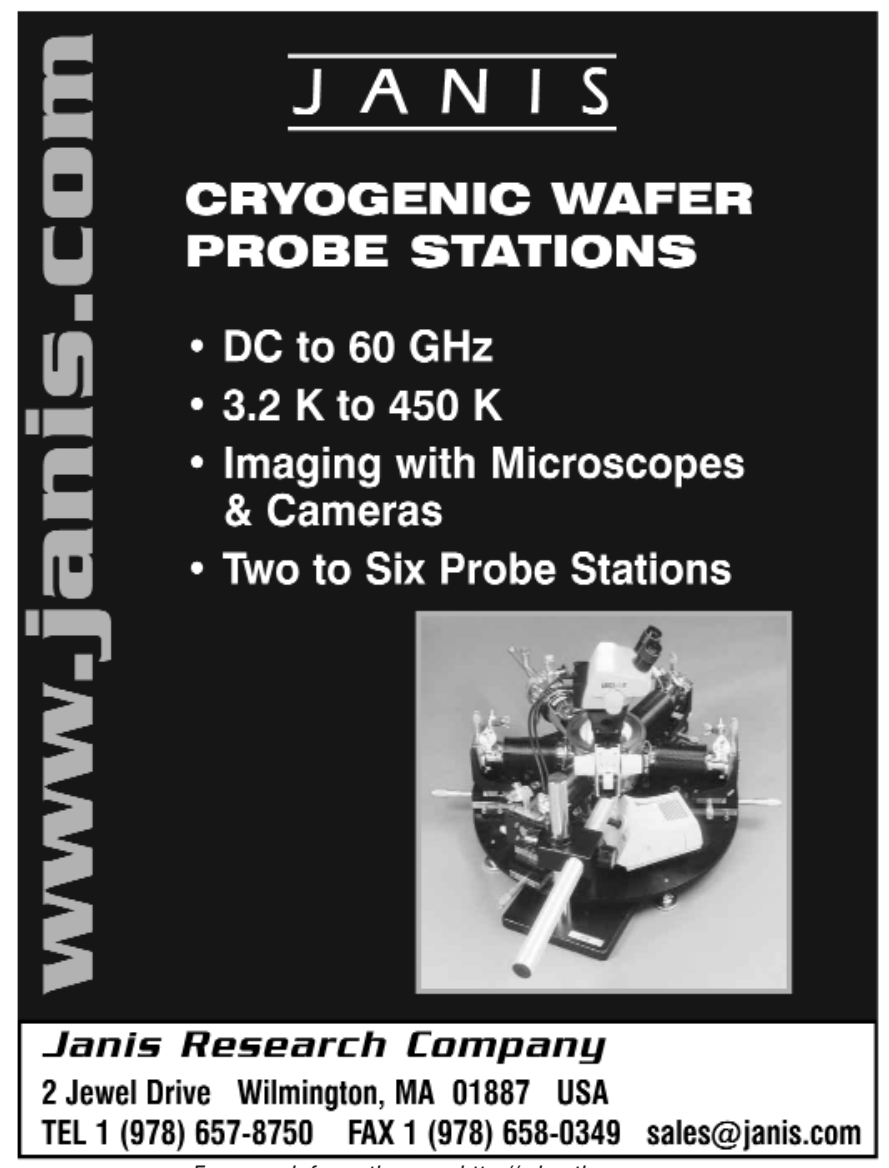

For more information, see http://advertisers.mrs.org

\section{Fiftieth Anniversary Symposium \\ Materials Science and Engineering Northwestern University}

\section{The Emergence, Current Frontiers, and Future Directions of Materials Science and Engineering}

Thursday, October $27 \bullet 9$ am to $5 \mathrm{pm}$

Friday, October $28 \cdot 9$ am to Noon

Hardin Hall

633 Clark Street

Evanston, Illinois

\section{Banquet}

Thursday, October $27 \bullet 6 \mathrm{pm}$

The Hotel Orrington

1603 Orrington Avenue

Evanston, Illinois

Symposium speakers will reflect on the development of the field of materials science and engineering as well as its current frontiers and future promise. Topics will include computational materials science, polymer and molecular electronics, materials design, materials for energy production, mechanical properties of nanomaterials, high performance ceramics, and materials for regenerative medicine.

For more information see the department web site at www.matsci.northwestern.edu/50th

For more information, see http://advertisers.mrs.org 